\title{
Plasma Mineralocorticoids, Glucocorticoids, and Progestins in Premature Infants: Longitudinal Study during the First Week of Life ${ }^{1}$
}

\author{
HELMUTH G. DOERR, WOLFGANG G. SIPPELL, HANS T. VERSMOLD, \\ FRANK BIDLINGMAIER, AND DIETER KNORR \\ Departments of Pediatrics [H.G.D., D.K.] and of Obstetrics and Gynecology, Div. Neonatology [H.T.V.], \\ University of Munich, Munich; the Department of Pediatrics [W.G.S.], University of Kiel, Kiel; and the \\ Department of Clinical Biochemistry [F.B.], University of Bonn, Bonn, FRG
}

\begin{abstract}
Plasma levels of aldosterone, corticosterone, 11-deoxycorticosterone, progesterone, 17-hydroxyprogesterone, 11-deoxycortisol, cortisol, and cortisone were measured simultaneously by a micromethod of multisteroid analysis in eight vaginally delivered premature infants (PI) of 33-36 wk gestation with uneventful peri- and postnatal course. Mean concentrations ( $\mathrm{ng} / \mathrm{ml})$ in umbilical arterial and in peripheral venous or capillary plasma sampled longitudinally at age $2 \mathrm{~h}$ to 7 days were compared with the same kind of data obtained from a group of 12 term infants (TI) who served as controls. Mean aldosterone was two to five times higher in PI than in TI (umbilical artery, $2 \mathrm{~h}$ to 7 days; $p<0.05$ ), whereas 11-deoxycorticosterone was lower in PI from $2 \mathrm{~h}(p<0.01)$ until 7 days (NS). Corticosterone was significantly higher in PI than TI at 6 and $24 \mathrm{~h}$ after birth, whereas cortisol was slightly lower (NS) in PI in umbilical artery and $2 \mathrm{~h}$ after birth, but higher $(p<0.02)$ at $6 \mathrm{~h}$, showing less variation in PI than in TI. 17-Hydroxyprogesterone levels in PI were two to three times higher $(p<0.02)$ during $6 \mathrm{~h}$ until 7 days after birth. The data suggest that PI are able to maintain high aldosterone levels in the early neonatal period. Higher levels of the active glucocorticoids (cortisol and corticosterone) seen after delivery point to a more stressful extrauterine adaptation of PI. Furthermore, the data demonstrate that the adrenal cortex is fully functioning in premature infants (33-36 wk gestation) as well as in term infants. (Pediatr Res 23: 525-529, 1988)
\end{abstract}

\section{Abbreviations}

RDS, respiratory distress syndrome

UA, umbilical artery

Aldo, aldosterone

DOC, 11-deoxycorticosterone

E, cortisone

$S$, 11-deoxycortisol

$B$, corticosterone

F, cortisol

P. progesterone

17OHP, 17-hydroxyprogesterone

Received June 8, 1987; accepted January 20, 1988

Reprint requests Helmuth G. Doerr, M.D., Department of Pediatrics, University of Munich, Lindwurmstr.4, D-8000 Muenchen 2, FRG.

Supported by Grant Do 273/1-2 from the Deutsche Forschungsgemeinschaft.

${ }^{1}$ Dedicated to Prof. Walter Teller on the occassion of his 60 th birthday.
Abrupt cessation of steroid supply from the placenta after severing the umbilical cord, and rapid postnatal involution of the fetal zone of the adrenal cortex dramatically changes the hormonal milieu of the fetus after birth. There is increasing evidence that the adrenal cortex plays an important role in the postnatal adaptation of newborns (1). For full-term healthy infants, data on plasma steroid levels in the neonatal period are available $(2,3)$, but studies on adrenal steroids in healthy premature infants are still lacking. Our micromethod of multisteroid analysis $(4,5)$ enabled us to measure simultaneously in a single small plasma sample individual mineralocorticoids, glucocorticoids, and progestins in premature infants at birth and longitudinally during the first hours and days of life.

Herein we assess in detail the adrenocortical function of healthy moderately premature infants after birth and provide reference data for the physiologically most important corticosteroids.

\section{MATERIALS AND METHODS}

Eight premature appropriate for gestational age infants (33-36 wk gestation) of both sexes (three males, five females) with uneventful peri- and postnatal courses were studied longitudinally from birth to day 7 . Their mothers $(20-36 \mathrm{yr})$ were healthy, and except for the preterm delivery their pregnancies were uncomplicated. None of the mothers received glucocorticoids for the prevention of RDS. Rupture of membranes had occurred between 2 and $36 \mathrm{~h}$ before delivery. There were no laboratory or clinical signs of amnionitis. All infants were born vaginally after spontaneous onset of labor with a median APGAR score of 7.5 (range 6-9) at $1 \mathrm{~min}$ and 9 (range $8-10$ ) at $5 \mathrm{~min}$. All premature infants received fluids increasing from 80 to $150 \mathrm{ml} / \mathrm{kg} /$ day from day 1 to 5 and between 150 to $180 \mathrm{ml} / \mathrm{kg} /$ day thereafter. Fluids were given intravenously as glucose $(8-15 \mathrm{~g} / \mathrm{kg} /$ day), sodium (2$4 \mathrm{mmol} / \mathrm{kg} /$ day), potassium $(1 \mathrm{mmol} / \mathrm{kg} /$ day, (except at day 1 , when no electrolytes were given), calcium gluconate $(0.5 \mathrm{~g} / \mathrm{kg} /$ day), amino acids ( $2 \mathrm{~g} / \mathrm{kg} /$ day), and trace elements. This regimen was gradually replaced by maternal breast-feeding. Serum electrolytes remained normal in all infants. None of the premature infants developed RDS. Twelve normal term infants, born vaginally, served as controls. Their data have been reported previously (2). Additional $S$ values and revised Aldo values of these infants were published recently (6). Umbilicoarterial steroid levels of the control infants were reported for the first time. Plasma samples of 100-250 $\mu \mathrm{l}$ were obtained during routine blood sampling from a peripheral vein or by heel prick at the age of 2 , $6,12,24 \mathrm{~h}$, and 4 and 7 days, and from the UA at the time of birth. Blood samples were collected into EDTA tubes and centrifuged immediately. The plasma was stored at $-20^{\circ} \mathrm{C}$ until assayed. 
Plasma levels of unconjugated Aldo, B, DOC, progesterone, 17-hydroxyprogesterone, $\mathrm{S}, \mathrm{F}$, and $\mathrm{E}$ were simultaneously measured from the same small plasma sample. The micromethod of multisteroid analysis has been previously described and evaluated $(4,5)$. In brief, it included the addition of tracer amounts of each of the eight steroids to a $250-\mu$ l plasma sample, extraction with methylene chloride, and a mechanized Sephadex LH-20 chromatography for the simultaneous separation of the steroids. Each isolated steroid fraction was quantitated by radioimmunoassay after branching off a small aliquot for internal standard recovery counting. Coefficients of variation of the complete assay (including extraction, chromatography, and radioimmunoassay) were between 6.9 and $14.5 \%$ within assays and between 11.9 and $16.3 \%$ between assays, for all eight steroids. However, each individual infant's plasma samples were analyzed in the same assay run including up to 30 samples.

For statistical comparisons (two-tailed) between the means of two samples either parametric (Student's $t$ test) or nonparametric tests of significance (Mann-Whitney U test) were used. Statistical comparisons of more than two means of paired samples, i.e. analyzing the postnatal course of the mean plasma levels of a given steroid, were made using the ranked analysis of variance according to Friedman in combination with Wilcoxon and Wilcox's multiple comparison of paired samples. Informed consent was obtained from all mothers and the study was approved by the local ethics committee.

\section{RESULTS}

Mineralocorticoids. Aldo. Mean Aldo levels (Fig. 1) were significantly higher in premature infants than in term infants from UA until day 7 . In premature infants, mean Aldo levels slightly decreased after birth $(2 \mathrm{~h})$, remained unchanged between 6 and $12 \mathrm{~h}$ after birth, and then further decreased to a minimum at day 4 . However, these variations were not significant.

$D O C$. DOC concentrations (Fig. 2) in premature and term infants decreased in parallel from UA to day 7 . Mean values in premature infants were constantly less than those of term infants throughout the study period. In prematures the decrease in DOC levels with age was significant between UA and $2 \mathrm{~h}(p<0.01)$, 6 and $12 \mathrm{~h}(p<0.02,12$ and $24 \mathrm{~h}(p<0.02) ; 24 \mathrm{~h}$ and 4 and 7 days, respectively $(p<0.01)$. The mean level at day 7 was only about $1 / 60$ of the UA level $(0.065$ versus $4.34 \mathrm{ng} / \mathrm{ml})$.

Glucocorticoids. $E$ and $S$. Mean E levels (Fig. 3) in premature infants, after an initial decline to half the UA level at $2 \mathrm{~h}(p<$ 0.02 ), remained almost unchanged. The postnatal course of $E$ was not significantly different between premature and term infants, although mean levels exhibited a more gradual fall in term infants. S levels in premature infants showed little variation during the study period and were not significantly different from those in term infants.

$B$ and $F$. Mean B levels (Fig. 4) initially declined in premature infants (UA to $2 \mathrm{~h}$; NS) and increased markedly from 2 to $6 \mathrm{~h}$ after birth $(p<0.01)$. Thereafter the levels again decreased constantly till $24 \mathrm{~h}$, when levels were significantly higher than at $12 \mathrm{~h}(p<0.05)$. After birth, B levels were significantly higher in premature than in term infants at 6 and $24 \mathrm{~h}$.

Mean F levels (Fig. 4) showed no significant variations in premature infants throughout the observation period. The levels at $6 \mathrm{~h}$ were significantly higher than in term infants. Thereafter, no significant differences were observed between the two groups.

Progestins. $P$. Mean P levels (Fig. 5) in premature infants declined rapidly by almost three orders of magnitude from UA until day 7. Accordingly, the differences were significant between $\mathrm{UA}$ and $2 \mathrm{~h}(p<0.002), 6$ and $12 \mathrm{~h}(p<0.05), 12$ and $24 \mathrm{~h}(p$ $<0.05), 24 \mathrm{~h}$ and 4 and 7 days, respectively $(p<0.001)$. In comparison with term infants, $\mathrm{P}$ levels were slightly lower during the entire study period.

17OHP. After an initial fall at $2 \mathrm{~h}$ to half the UA levels $(p<$

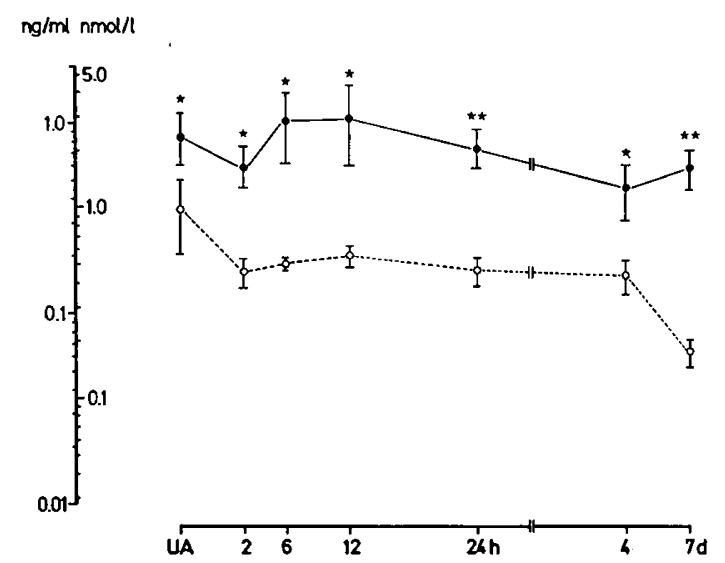

Fig. 1. Plasma Aldo concentrations (mean \pm SEM) in UA and from $2 \mathrm{~h}$ to 7 days of age in premature infants (33-36 wk of gestation). (•) premature infants; $(O)$ control term infants. Levels of significance ${ }^{*} p<$ $0.05 ;{ }^{* *} p<0.02 ;{ }^{* * *} p<0.001$.

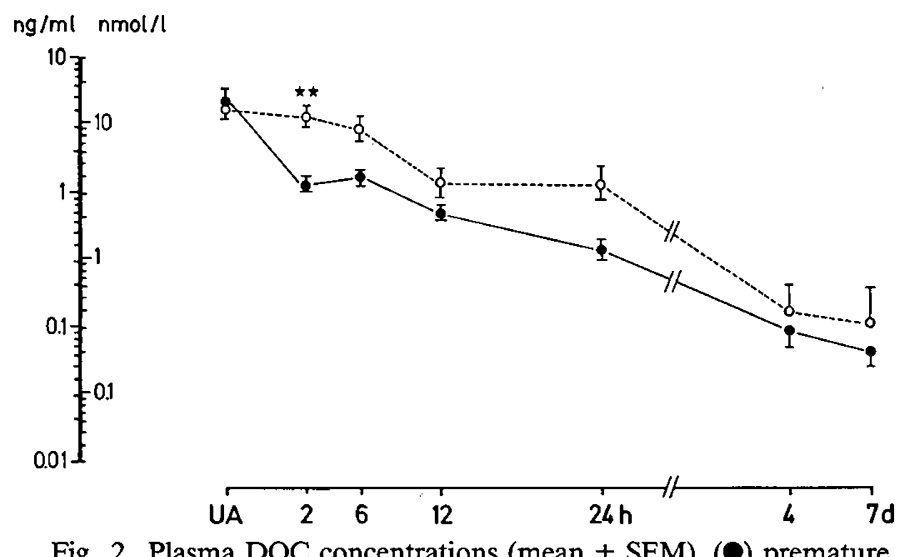

Fig. 2. Plasma DOC concentrations (mean \pm SEM). (๑) premature infants; $(O)$ control term infants. For further details see legend to Figure 1.

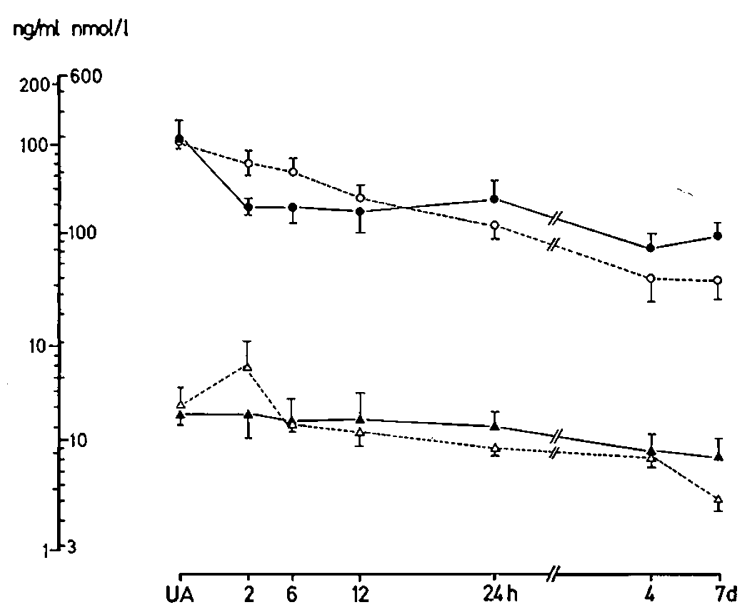

Fig. 3. Plasma $E(O)$ and $S(\triangle)$ concentrations (mean $\pm S E M)$. Closed symbols, premature infants; open symbols, control term infants. For further details see legend to Figure 1.

0.002), and little change until $6 \mathrm{~h}$ after birth, mean 17-OHP levels (Fig. 5) again decreased significantly in premature infants between 12 and $24 \mathrm{~h}(p<0.05)$. They did not vary significantly thereafter. Mean 17-OHP levels in UA were significantly lower in premature infants than in term infants, whereas later, from 6 $h$ until 7 days after birth, they were significantly higher in the 
$\mathrm{ng} / \mathrm{ml} \mathrm{nmol} / \mathrm{l}$

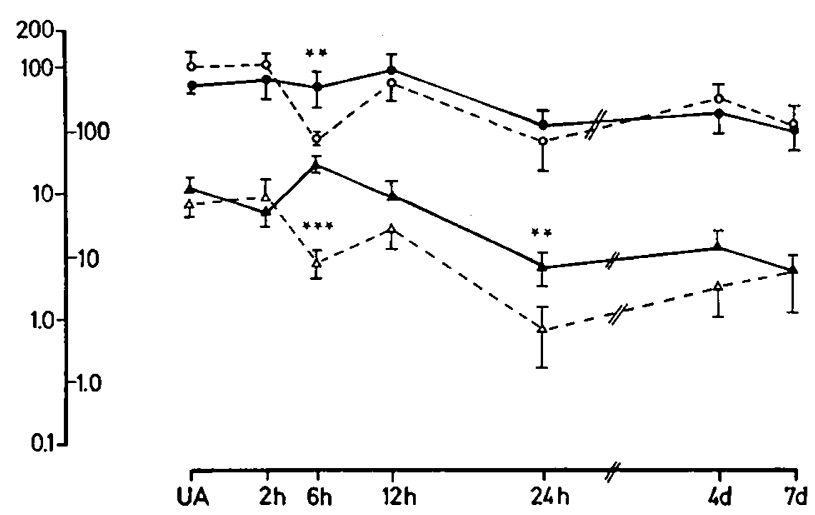

Fig. 4. Plasma $\mathrm{F}(\mathrm{O})$ and $\mathrm{B}(\Delta)$ concentrations (mean \pm SEM). Closed symbols, premature infants; open symbols, control term infants. For further details see legend to Figure 1.

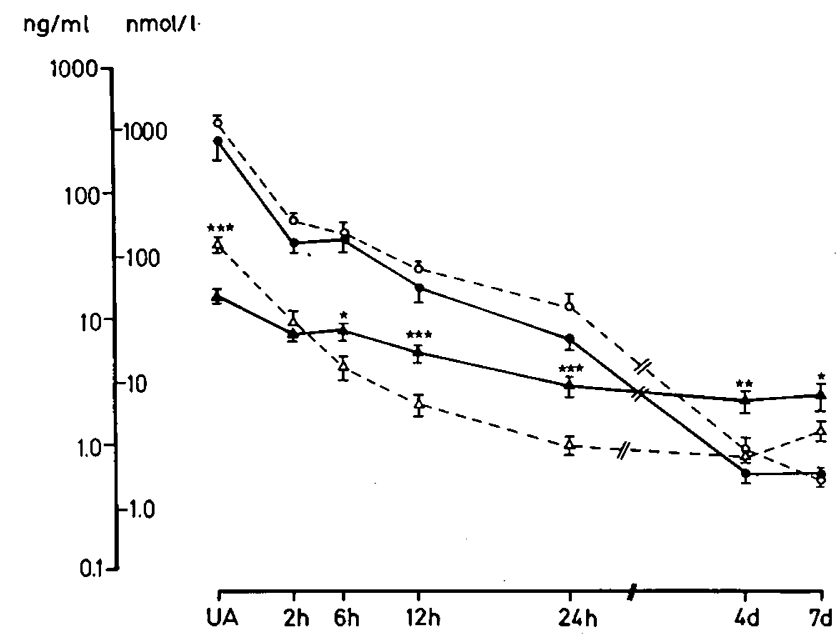

Fig. 5. Plasma $P(O)$ and $17 \mathrm{OHP}(\Delta)$ concentrations (mean \pm SEM). Closed symbols, premature infants; open symbols, control term infants. For further details see legend to Figure 1.

premature group. On the whole, term infants showed a 2.5 times steeper fall in 17OHP than premature infants during the first days after birth.

For easier reference, numerical results of the eight steroid hormones in our two groups of PI and TI are listed in Table 1.

\section{DISCUSSION}

At birth, the fetal adrenal cortex consists primarily of the fetal zone $(80 \%)$, which involutes rapidly after birth (7). Only the definitive zone $(20 \%)$ produces significant amounts of biologically active $\Delta 4$-corticosteroids, whereas the fetal zone secretes high levels of $\Delta 5-3-\beta$-hydroxysteroids such as pregnenolone and dehydroepiandrosterone sulfate. Whereas the steroids of the fetal zone have been well evaluated (8-10), there is still relatively little information about the steroids produced by the definitive zone of the adrenal cortex in premature infants. Using our micromethod, we followed the main mineralocorticoids, glucocorticoids, and progestins in premature infants during the 1st wk after birth, i.e. during an important period of adaptation from intrato extrauterine life.

Mineralocorticoids. To our knowledge, there are no reports on plasma Aldo and DOC levels in premature infants studied longitudinally during the first hours and days of life. Similarly, in full-term infants, most data were obtained in random samples (11-13). Surprisingly, the two mineralocorticoids showed a somewhat divergent pattern in premature infants. Whereas Aldo levels were higher in premature than in term infants, DOC levels were lower in the premature group, suggesting a minor role for DOC in the regulation of sodium homeostasis.

Due to an increased urinary sodium loss in premature infants their renin-angiotensin-Aldo axis is markedly elevated (14-16). High urinary levels of tetrahydroaldosterone suggest renal tubular unresponsiveness of Aldo $(17,18)$. Our longitudinal data on elevated plasma Aldo levels during the 1st wk of life support these findings and compare well with the results of Siegel et al. (19). Their study was limited to the 2 nd day of life. High Aldo levels in premature infants may be of physiological importance because it has been speculated that Aldo itself is an inductor of proximal tubular function (20).

Glucocorticoids. Most data on adrenocortical function in premature infants only provide the measurement of $F$ levels in mixed cord plasma at the time of delivery, as recently reviewed by Murphy (21) and in random samples during the neonatal period (22-24). However, measurement of mixed cord plasma steroid levels may not reflect true fetal function, just as F levels alone without the knowledge of other glucocorticoids may give only a limited insight into adrenococortical function.

In 1963, Kenny et al. (25) reported a satisfactory F production rate of premature infants, a finding that was questioned by Aarskog (26). Since then various reports demonstrated the ability of the adrenal cortex of premature infants to respond to stress with an increased output of $\mathrm{F}$ comparable to that of full-term infants $(27,28)$. Our data of somewhat lower fetal (umbilical artery) $\mathrm{F}$ levels, as with findings in mixed cord blood (29) probably indicate that vaginal delivery at 33-36 wk of gestation is slightly less stressful than delivery at term. However, the higher $\mathrm{F}$ and $\mathrm{B}$ levels in premature infants after birth point to a more stressful adaptation to extrauterine life. This result agrees with the finding of high excretion of urinary free $F$ in premature infants (30), and demonstrates the ability of the adrenal cortex to secrete sufficient amounts of active glucocorticoids (31).

The physiological significance of the elevated levels of the active glucocorticoids ( $F$ and $B$ ) in premature infants, particularly at $6 \mathrm{~h}$ after birth, is not yet clear. F plays multiple roles during neonatal adaptation. For example, by enzyme induction it effects the functional maturation of many organs essential for extrauterine life, e.g. lungs, liver, intestine, elevates blood glucose levels, and may have a role in the neonatal immune system $(32,33)$.

Regarding the inactive glucocorticoids, i.e. $\mathrm{E}$ and $\mathrm{S}$, there is little information in premature infants. Klein et al. (34) have not stated the individuals' ages at blood sampling, thus precluding a comparison with our data on $\mathrm{E}$. The initial decline of $\mathrm{E}$ levels from UA to $2 \mathrm{~h}$ is somewhat steeper in premature than in term infants, but thereafter the levels do not vary significantly between both groups. They are in the same range as the $F$ levels in term infants, indicating that $\mathrm{E}$, although biologically inactive, is a major blood corticosteroid in neonatal plasma (35). S levels have never been longitudinally studied in premature infants. No significant difference could be found between premature and term infants at any time throughout the study period.

Progestins. The rapid postnatal decline of progesterone levels in premature infants is in agreement with reports in term infants and reflects the predominant placental origin of this steroid (2, 3). Our data are comparable to those of Conly et al. (36) who studied only three premature infants serially, and to random data of Forest and Cathiard (37) and Tapanainen et al. (38).

17OHP levels also declined postnatally in premature infants but not to the same extent as in term infants, so that the levels were higher in premature infants after $6 \mathrm{~h}$ of age. Random data (39) agree with our results. The reason is still unclear; however, a relative immaturity of the 21-hydroxylase enzyme system might play a role. This finding is clinically important because determinations of 17-OHP levels are widely used for early diagnosis of congenital adrenal hyperplasia (40). Therefore, it is necessary to take into account the gestational age of the neonates in order 
Table 1. Plasma steroid levels ( $\mathrm{ng} / \mathrm{ml}$; mean \pm SEM) in premature infants (PI) and term infants (TI)*

\begin{tabular}{|c|c|c|c|c|c|c|c|c|c|c|c|c|c|c|}
\hline & \multicolumn{2}{|c|}{ UA } & \multicolumn{2}{|c|}{$2 \mathrm{~h}$} & \multicolumn{2}{|c|}{$6 \mathrm{~h}$} & \multicolumn{2}{|c|}{$12 \mathrm{~h}$} & \multicolumn{2}{|c|}{$24 \mathrm{~h}$} & \multicolumn{2}{|c|}{4 days } & \multicolumn{2}{|c|}{7 days } \\
\hline & PI & TI & PI & TI & PI & TI & PI & TI & PI & TI & PI & TI & PI & TI \\
\hline \multirow[t]{2}{*}{ Aldo } & 0.87 & 0.35 & 0.61 & 0.17 & 1.06 & 0.19 & 1.10 & 0.20 & 0.77 & 0.17 & 0.46 & 0.16 & 0.59 & 0.06 \\
\hline & 0.25 & 0.15 & 0.15 & 0.03 & 0.41 & 0.01 & 0.50 & 0.03 & 0.16 & 0.03 & 0.15 & 0.03 & 0.14 & 0.01 \\
\hline \multirow[t]{2}{*}{ DOC } & 4.34 & 4.10 & 1.14 & 3.60 & 1.24 & 2.97 & 0.69 & 1.18 & 0.38 & 1.16 & 0.09 & 0.13 & 0.06 & 0.11 \\
\hline & 1.19 & 0.46 & 0.13 & 0.65 & 0.17 & 0.61 & 0.09 & 0.27 & 0.07 & 0.38 & 0.02 & 0.07 & 0.02 & 0.07 \\
\hline \multirow[t]{2}{*}{ B } & 11.5 & 8.51 & 7.14 & 9.28 & 17.5 & 2.82 & 9.58 & 5.23 & 2.54 & 0.83 & 3.84 & 1.85 & 2.46 & 2.46 \\
\hline & 2.80 & 2.12 & 1.71 & 3.66 & 2.34 & 0.78 & 3.08 & 1.64 & 0.75 & 0.42 & 1.41 & 0.88 & 0.80 & 1.35 \\
\hline \multirow[t]{2}{*}{$\mathrm{F}$} & 73.5 & 102.6 & 81.5 & 104.3 & 72.6 & 28.1 & 96.7 & 76.4 & 36.6 & 27.2 & 44.5 & 57.0 & 31.6 & 34.8 \\
\hline & 10.4 & 35.4 & 25.3 & 25.7 & 23.8 & 3.20 & 38.8 & 21.4 & 9.40 & 12.0 & 14.0 & 16.5 & 10.4 & 15.7 \\
\hline \multirow[t]{2}{*}{ E } & 108.5 & 107.3 & 49.9 & 83.1 & 49.5 & 74.9 & 48.4 & 56.8 & 54.9 & 41.1 & 31.3 & 22.6 & 36.3 & 22.0 \\
\hline & 23.2 & 9.10 & 4.30 & 11.2 & 8.70 & 15.6 & 11.5 & 7.20 & 13.3 & 6.30 & 5.70 & 5.40 & 5.30 & 4.60 \\
\hline \multirow[t]{2}{*}{$S$} & 4.67 & 5.25 & 4.68 & 8.12 & 4.26 & 4.20 & 4.42 & 3.88 & 4.17 & 3.23 & 3.11 & 2.94 & 2.91 & 1.83 \\
\hline & 0.43 & 1.01 & 1.05 & 2.98 & 1.36 & 0.29 & 1.61 & 0.51 & 0.77 & 0.29 & 0.68 & 0.11 & 0.76 & 0.24 \\
\hline \multirow[t]{2}{*}{$\mathbf{P}$} & 256.7 & 340.0 & 39.0 & 57.3 & 40.6 & 46.3 & 17.1 & 24.0 & 6.79 & 12.5 & 0.56 & 0.88 & 0.53 & 0.50 \\
\hline & 80.3 & 50.9 & 6.40 & 6.90 & 9.30 & 9.80 & 3.60 & 3.10 & 1.49 & 2.86 & 0.11 & 0.26 & 0.18 & 0.12 \\
\hline \multirow[t]{2}{*}{ 17-OHP } & 14.3 & 37.2 & 7.13 & 8.86 & 7.40 & 3.98 & 5.05 & 1.99 & 2.86 & 0.94 & 2.14 & 0.79 & 2.37 & 1.24 \\
\hline & 0.47 & 3.65 & 0.96 & 2.03 & 1.24 & 0.90 & 0.71 & 0.38 & 0.44 & 0.16 & 0.40 & 0.09 & 0.58 & 0.20 \\
\hline
\end{tabular}

* Data from References 2 and 6.

to avoid false-positive diagnoses of congenital adrenal hyperplasia.

\section{CONCLUSIONS}

Substantial changes occur in adrenocortical function of healthy premature infants during the vitally important period of transition from intra- to extrauterine life.

Despite a tremendous fall of circulating precursor steroids and altered steroid catabolism due to immature metabolizing enzymes in liver, kidney, or adrenal cortex, the present data provide evidence that the adrenal cortex of premature infants (33-36 wk of gestation) is functioning as well as in full-term infants and is able to provide gluco- and mineralocorticoid activity in the 1st wk of life. Further studies must answer the question whether this conclusion holds true for the very low birth weight infant.

Acknowledgments. The authors express their appreciation to the physicians and nurses, and to Mrs. Gertrud Himml and her midwife colleagues at the Department of Gynecology and Obstetrics, Klinikum Grosshadern, University of Munich. We also thank Mrs. Reinhild Joswig and Mrs. Marion Herrmann for their technical assistance.

\section{REFERENCES}

1. Reynolds JW 1976 Fetoplacental and neonatal steroid endocrinology. In: Smith CA, Nelson NM (eds) The physiology of the Newborn Infant. Charles C Thomas, Springfield IL, pp. 664-735

2. Sippell WG, Becker H, Versmold HT, Bidlingmaier F, Knorr D 1978 Longitudinal studies of plasma aldosterone, corticosterone, deoxycorticosterone, progesterone, 17-hydroxyprogesterone, cortisol and cortisone determined simultaneously in mother and child at birth and during the early neonatal period. I. Spontaneous delivery. J Clin Endocrinol Metab 46:971-985

3. Kojima S, Yanaihara T, Nakayama T 1981 Serum steroid levels in children at birth and in early neonatal period. Am J Obstet Gynecol 140:961-965

4. Sippell WG, Lehmann P, Hollmann G 1975 Automation of multiple Sephadex LH-20 column chromatography for the simultaneous separation of plasma corticosteroids. J Chromatogr 108:305-312

5. Sippell WG, Bidlingmaier F, Becker H, Bruenig T, Doerr $\mathrm{H}$, Hahn $\mathrm{H}$, Golder W, Hollmann G, Knorr D 1978 Simultaneous radioimmunoassay of plasma aldosterone, corticosterone, 11-deoxycorticosterone, progesterone, 17-hydroxyprogesterone, 11-deoxycortisol, cortisol and cortisone. J Steroid Biochem 9:63-74

6. Doerr HG, Sippell WG, Versmold HT, Bidlingmaier F, Knorr D 1987 Plasma aldosterone and 11-deoxycortisol in newborn infants: A reevaluation. J Clin Endocrinol Metab 65:208-210

7. Lanman JT 1961 The adrenal gland in the human fetus. An interpretation of its physiology and unusual development pattern. Pediatrics 27:140-158

8. de Peretti E, Forest MG 1976 Unconjugated dehydroepiandrosterone plasma levels in normal subjects from birth to adolescence in human: the use of a sensitive radioimmunoassay. J Clin Endocrinol Metab 43:982-991

9. Turnipseed MR, Bentley K, Reynolds JW 1976 Serum dehydroepiandrosterone sulfate in premature infants and infants with intrauterine growth retardation. $\mathrm{J}$ Clin Endocrinol Metab 43:1219-1225

10. Grueters A, Korth-Schuetz S 1982 Longitudinal study of plasma dehydroepiandrosterone sulfate in preterm and fullterm infants. J Clin Endocrinol Metab 55:314-320

11. Beitins IZ, Bayard F, Levitsky L, Ances G, Kowarski A, Migeon CJ 1972 Plasma aldosterone concentrations at delivery and during the newborn period. I Clin Invest 51:386-394

12. Raux-Eurin MC, Pham-Huu-Trung MT, Marrec D, Girard F 1977 Plasma aldosterone concentrations during the neonatal period. Pediatr Res 11:182185

13. Sparano F, Sciarra F, Natali G, Mercuri MA, Odoardi A, Colangelo E 1978 Behaviour of plasma renin activity and aldosterone during the first $72 \mathrm{~h}$ of life. Clin Endocrinol 8:207-211

14. Kotchen TA, Strickland AL, Rice TW, Walters DR 1972 A study of the reninangiotensin system in newborn infants. J Pediatr 80:938-946

15. Sulyok E, Nemeth M, Tenyi I, Csaba I, Gyoery E, Ertl T, Varga F 1979 Postnatal development of renin-angiotensin-aldosterone system, RAAS, in relation to electrolyte balance in premature infants. Pediatr Res 13:817-820

16. Al-Dahhan J, Haycock GB, Chantler C, Stimmler L 1983 Sodium homeostasis in term and preterm neonates. I. Renal aspects Arch Dis Child 58:335-342

17. Honour JW, Valman HB, Shackleton CHL 1977 Aldosterone and sodium homeostasis in preterm infants. Acta Paediatr Scand 66:103-109

18. Solc J, Knorr D 1974 Die Wirkung von Aldosteron und Spirolacton auf die Ausscheidung von Natrium und Kalium im Harn bei Neugeborenen und Saeuglingen. Z Kinderheilk 116:143-152

19. Siegel SR, Fisher DA, Oh W 1974 Serum aldosterone concentrations related to sodium balance in the newborn infant. Pediatrics 53:410-413

20. Aperia A, Larsson L, Zetterstroem R 1981 Aldosterone, an inductor of proximal tubular function. In: Physiological and Biochemical Basis for Perinatal Medicine. Karger, Basel, pp 256-261.

21. Murphy BEP 1983 Human fetal serum cortisol levels at delivery: a review. Endocr Rev 4:150-154

22. Forest MG, Lecoq A, Salle B, Bertrand J 1981 Does neonatal phenobarbital treatment affect testicular and adrenal functions and steroid binding in plasma in infancy? J Clin Endocrinol Metab 52:103-110

23. Noguchi A, Reynolds JW 1978 Serum cortisol and dehydroepiandrosterone sulfate responses to adrenocorticotropin stimulation in premature infants. Pediatr Res 12:1057-1061

24. Salvadori B, Benassi L, Merialdi A, Coppola F, Pini L, Cacciatore A 1977 Feto-neonatal hormonology in premature delivery. J Steroid Biochem 8:385386

25. Kenny FM, Malvaux P, Migeon CJ 1963 Cortisol production rate in newborn babies, infants and children. Pediatrics 31:360-373

26. Aarskog D 1965 Cortisol in the newborn infant. Acta Paediatr Scand [Suppl] 118:23-30

27. Sybulski S 1977 Umbilical cord plasma cortisol levels in association with pregnancy complications. Obstet Gynecol 50:308-312

28. Kauppila A, Koivisto M, Pukka M, Tuimala R 1978 Umbilical cord and neonatal cortisol levels: effect of gestational and neonatal factors. Obstet Gynecol 52:666-672

29. Murphy BEP 1974 Cortisol and cortisone levels in the cord blood at delivery of infants with and without respiratory distress syndrome. Am J Obstet Gynecol 119:1112-1120

30. Siamopoulou-Mavridou A, Mavridis AK, Vizandiadis A, Harsoulis P 1986 Free urinary cortisol immunoreactive levels in premature and full term 
infants. Acta Paediatr Scand 75:919-922

31. Lilien LD, Rosenfield RL, Baccaro MM, Pildes RS 1979 Hyperglycemia in stressed small premature neonates. J Pediatr 94:454-459

32. Liggins GC 1976 Adrenocortical-related maturational events in the fetus. Am J Obstet Gynecol 126:931-941

33. Murphy BEP 1979 Cortisol and cortisone in human fetal development. J Steroid Biochem 11:509-513

34. Klein GP, Baden M, Giroud CJP 1973 Quantitive measurment and significance of five plasma corticosteroids during the perinatal period. J Clin Endocrinol Metab 36:944-950

35. Hillman DA, Giroud CJP 1965 Plasma cortisone and cortisol levels at birth and during the neonatal period. J Clin Endocrinol Metab 25:243-248

36. Conly PW, Morrison T, Sandberg TH, Cleveland WW 1970. Concentration of progesterone in the plasma of mothers and infants at the time of birth Pediatr Res 4:76-81

37. Forest MG, Cathiard A-M 1978 Ontogenetic study of plasma 17-hydroxyprogesterone in the human. I. Postnatal period: Evidence for a transient ovarian activity in infancy. Pediatr Res 12:6-11

38. Tapanainen J, Huhtaniemi I, Koivisto M, Kujansuu E, Tuimala R, Vihko R 1984 Hormonal changes during the perinatal period: FSH, prolactin and some steroid hormones in the cord blood and peripheral serum of preterm and fullterm female infants. J Steroid Biochem 20:1153-1156

39. Murphy JF, Joyce BG, Dyas J, Hughes IA 1983 Plasma 17-hydroxyprogesterone in ill newborn infants. Arch Dis Child 58:532-534

40. Youssefnejadian E, David R 1975 Early diagnosis of congenital adrenal hyperplasia by measurement 17-hydroxyprogesterone. Clin Endocrinol 4:451-454 